This article was downloaded by: [Universita' Milano Bicocca]

On: 10 October 2013, At: 02:59

Publisher: Routledge

Informa Ltd Registered in England and Wales Registered Number: 1072954 Registered office: Mortimer House, 37-41 Mortimer Street, London W1T 3J H, UK

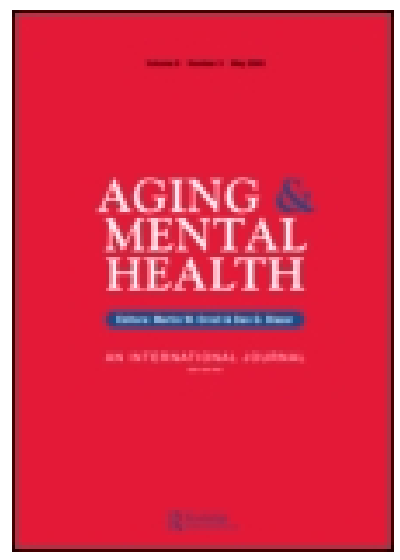

\author{
Aging \& Mental Health \\ Publication details, including instructions for authors and subscription information: \\ http:// www.tandfonline.com/loi/ camh20
}

\title{
Addendum to 'Efficacy of music therapy treatment based on cycles of sessions: A randomised controlled trial' (Raglio et al., 2010)
}

\author{
A. Raglio ${ }^{a b}$, G. Bellelli $^{c}$, D. Traficante ${ }^{d}$, M. Gianotti $^{a}$, M.C. Ubezio $^{a}$, S. Gentile ${ }^{e}$, \\ D. Bellandi ${ }^{a}$, D. Villani ${ }^{f} \& M$. Trabucchi ${ }^{9}$ \\ ${ }^{\text {a }}$ Sospiro Foundation, Cremona, Italy \\ ${ }^{b}$ Interdem Group (Psycho-Social Interventions in Dementia), EU \\ ${ }^{c}$ Department of Clinical and Preventive Medicine, Geriatric Chair, Bicocca University, \\ Milan and Geriatric Research Group, Brescia, Italy \\ ${ }^{\mathrm{d}}$ Department of Psychology and Education Technologies Research Center, Catholic \\ University, Milan, Italy \\ ${ }^{\text {e }}$ Alzheimer's Evaluation Unit, Ancelle della Carità Hospital , Cremona , Italy \\ ${ }^{f}$ Rehabilitation and Alzheimer's Evaluation Unit, Figlie di S. Camillo Hospital , Cremona , \\ Italy \\ ${ }^{9}$ Tor Vergata University, Rome and Geriatric Research Group , Brescia , Italy \\ Published online: $06 \mathrm{~J}$ an 2012.
}

\begin{abstract}
To cite this article: A. Raglio, G. Bellelli, D. Traficante, M. Gianotti , M.C. Ubezio, S. Gentile, D. Bellandi , D. Villani $\&$ M. Trabucchi (2012) Addendum to 'Efficacy of music therapy treatment based on cycles of sessions: A randomised controlled trial' (Raglio et al., 2010), Aging \& Mental Health, 16:2, 265-267, DOI: 10.1080/13607863.2011.630376
\end{abstract}

To link to this article: http:// dx.doi.org/ 10.1080/13607863.2011.630376

\section{PLEASE SCROLL DOWN FOR ARTICLE}

Taylor \& Francis makes every effort to ensure the accuracy of all the information (the "Content") contained in the publications on our platform. However, Taylor \& Francis, our agents, and our licensors make no representations or warranties whatsoever as to the accuracy, completeness, or suitability for any purpose of the Content. Any opinions and views expressed in this publication are the opinions and views of the authors, and are not the views of or endorsed by Taylor \& Francis. The accuracy of the Content should not be relied upon and should be independently verified with primary sources of information. Taylor and Francis shall not be liable for any losses, actions, claims, proceedings, demands, costs, expenses, damages, and other liabilities whatsoever or howsoever caused arising directly or indirectly in connection with, in relation to or arising out of the use of the Content.

This article may be used for research, teaching, and private study purposes. Any substantial or systematic reproduction, redistribution, reselling, loan, sub-licensing, systematic supply, or distribution in any form to anyone is expressly forbidden. Terms \& Conditions of access and use can be found at http:// www.tandfonline.com/page/terms-and-conditions 


\title{
Addendum to 'Efficacy of music therapy treatment based on cycles of sessions: A randomised controlled trial' (Raglio et al., 2010)
}

\author{
A. Raglio ${ }^{\text {ab* }}$, G. Bellelli ${ }^{\mathrm{c}}$, D. Traficante ${ }^{\mathrm{d}}$, M. Gianotti ${ }^{\mathrm{a}}$, M.C. Ubezio ${ }^{\mathrm{a}}$, S. Gentile ${ }^{\mathrm{e}}$, D. Bellandi ${ }^{\mathrm{a}}$, \\ D. Villanif ${ }^{\mathrm{f}}$ and M. Trabucchi ${ }^{\mathrm{g}}$ \\ ${ }^{a}$ Sospiro Foundation, Cremona, Italy; ${ }^{b}$ Interdem Group (Psycho-Social Interventions in Dementia), EU; \\ ${ }^{c}$ Department of Clinical and Preventive Medicine, Geriatric Chair, Bicocca University, Milan and Geriatric Research Group, \\ Brescia, Italy; ${ }^{d}$ Department of Psychology and Education Technologies Research Center, Catholic University, Milan, Italy; \\ 'Alzheimer's Evaluation Unit, Ancelle della Carità Hospital, Cremona, Italy; ${ }^{f}$ Rehabilitation and Alzheimer's \\ Evaluation Unit, Figlie di S. Camillo Hospital, Cremona, Italy; ${ }^{g}$ Tor Vergata University, Rome and \\ Geriatric Research Group, Brescia, Italy
}

(Received 28 July 2011; final version received 3 October 2011)

\begin{abstract}
Objectives: The aim of this paper is to provide further detail about the results of a randomised controlled study published in this journal (Raglio et al., 2010, 14, 900-904), in which we assessed the efficacy of music therapy (MT) on the behavioural disturbances in people with moderate-severe dementia.

Methods: Sixty patients were randomly assigned to the experimental (MT and standard care) and control group (standard care only). The experimental group received three cycles of 12 MT sessions each, three times a week. Each cycle of treatment was followed by one month of washout period, while the standard care activities continued over time.

Results: The impact of the treatment (12 MT sessions) was reliable on NPI global scores, as the interaction Time by Group was significant $\left(\mathrm{F}_{1,49}=4.09, p=0.049\right)$. After the end of the treatment the NPI global scores of the experimental and control groups tended to become similar, as both groups worsened (Time effect: $F_{1,48}=4.67$, $\mathrm{p}=0.014)$ and the difference between them disappeared $(\mathrm{F}<1)$. Interaction Time by Group was not significant. Conclusions: The study confirms that active MT determines a positive response and can amplify and strengthen the efficacy of therapeutic interventions towards people with dementia.
\end{abstract}

Keywords: psychological and behavioural symptoms; psychosocial interventions; alzheimer's disease; other dementias

\section{Introduction}

The aim of this article is to provide further details about the results of a randomised controlled study published on this journal (Raglio et al., 2010), in which we assessed the efficacy of a Music Therapy (MT) treatment based on cycles of sessions on the behavioural disturbances in people with moderate to severe dementia. In that paper we showed that NPI total scores were lower in the experimental group than in the control group for the entire period of the treatment, but further analyses have been requested in order to better assess the role of the treatment in determining improvement.

\section{Methods}

Sixty patients from five nursing homes (NHs) (Sospiro Foundation Cremona; Ulivi NH Salò, Brescia; Piccinelli Foundation and S. Chiara NH, Bergamo and IRCCS Don Gnocchi Foundation, Milan, Italy) were eligible and were randomly assigned to experimental or control group (for the full description of the sample and for inclusion criteria, see Raglio et al., 2010).

All patients in the experimental and control groups received standard care (i.e. educational and entertainment activities such as reading a newspaper, performing physical activities, etc.). In addition, the experimental group received three cycles of $12 \mathrm{MT}$ sessions each, three times a week. Each session involved a group of three patients and lasted $30 \mathrm{~min}$. Each cycle of treatment was followed by one month of washout period, while the standard care activities continued over time. To assess the effects of the intervention on behaviour, the Neuropsychiatric Inventory (NPI) was administered at each point of assessment (from T0 to T7).

Repeated measures analysis of variance (R-ANOVA) was used to examine NPI total scores, over time, with Group (experimental versus control) as the between factor and Time as the repeated factor. Analyses were previously conducted using three time periods: baseline (T0), end of the treatment period (T5), and follow-up one month after the end of the treatment (T6). These analyses showed a significant 
effect for time, but the Group x Time interaction was not significant. These results indicated no difference between treatment and control groups. We then considered all seven times the NPI scores were obtained, beginning with the baseline period (T0) through to the follow up periods (T6-T7). We identified three different phases: the change from a baseline condition to the experience of a MT treatment; the period of the alternation between treatment cycles and washouts; the end of the treatment and the next period of absence of treatment. We analysed the effect of music therapy considering the impact of treatment (T0 versus T1), the period during the treatment (from $\mathrm{T} 1$ to $\mathrm{T} 5$ ), and the maintenance of the possible effect after the end of the treatment (follow-ups: from T5 to T7). Based on these analyses, we suggested in the previous paper that those findings indicated improvement in NPI scores from baseline (T0) to after the initial administration of the treatment (T1). R-ANOVA results for those findings appear below.

\section{Results}

Seven patients dropped out (three in the experimental and four in the control group), and two patients with NPI baseline scores higher than 2.5 SD over the mean were excluded from the analysis, to reduce the over-all variability within groups.

The impact of the treatment (T0 vs T1, Figure 1a) was reliable on NPI global scores, as the interaction Time by Group was significant $\left(\mathrm{F}_{1,49}=4.09\right.$, $p=0.049)$. NPI scores in the control group slightly increased (T0: $M=24.46$; $\mathrm{T} 1: \mathrm{M}=25.17$ ), while in the experimental group scores decreased (T0: $M=20.26$; $\mathrm{T} 1: \mathrm{M}=17.11)$. The difference between groups was maintained during the period of treatment (T1-T5, Figure 1b). Both groups improved (Time effect:
$\mathrm{F}_{4,46}=7.59, \quad p<0.001$ ), but remained at different levels of behavioural disturbances on the NPI (Group effect: $\left.F_{1,49}=3.92, p=0.05\right)$. The interaction of Time by Group was not significant. After the end of the treatment (T5-T7, Figure 1c) the NPI global scores of the experimental and control groups tended to converge, as both groups worsened (Time effect: $\left.\mathrm{F}_{1,48}=4.67, p=0.014\right)$ and the difference between them was no longer significant $(F<1)$. The Time by Group interaction was not significant.

As for the analysis of NPI subscale items, the poor metric properties of the scales, due to the high variability of the data in front of small mean values did not allow the use of parametric statistics. As the effect of the interactions cannot be estimated by nonparametric procedures (e.g. Friedmann's ANOVA) we chose not to consider those data, but to focus only on the NPI total score.

\section{Discussion}

The study confirms a positive response of people with moderate to severe dementia to active music therapy. We found that, in the experimental group, the main effect of music therapy sessions on BPSD, associated to a significant interaction Group $\times$ Time, was obtained after the first cycle, while the further cycles of music therapy sessions worked at maintaining the difference between the two groups. During that period, in fact, both the experimental and control groups improved, but the experimental group maintained its advantage over time. When the music therapy sessions were finished, the experimental group gradually worsened on the NPI. By the 4 (T6) and 8 (T7) follow ups, there were no differences between treatment and control group.

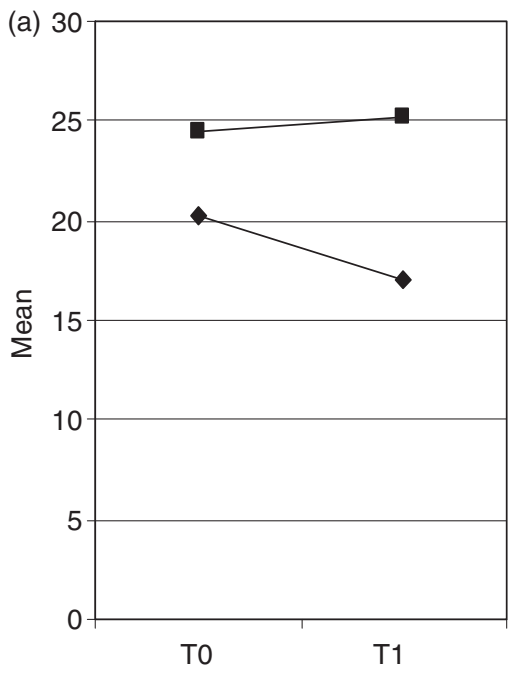

(b)

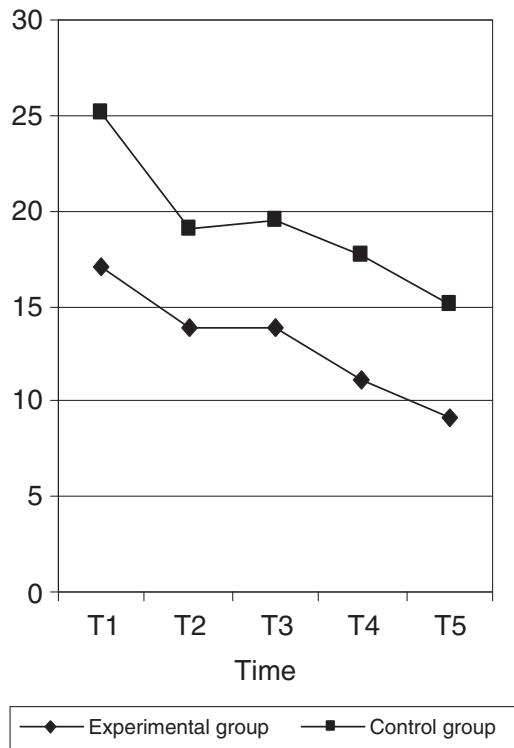

(c) 30

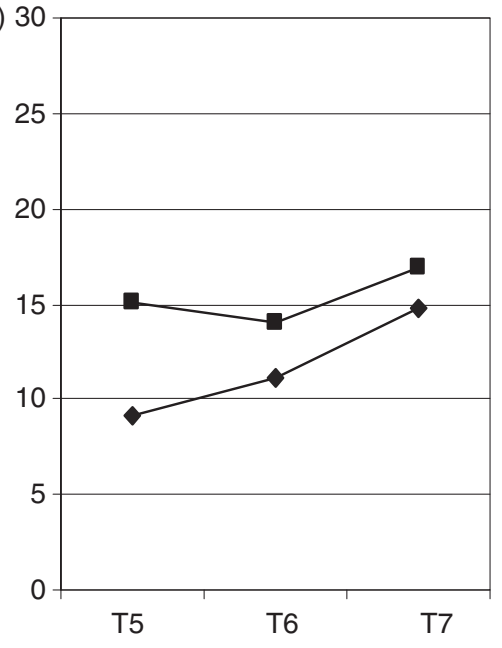

Figure 1. Comparisons of the average NPI global scores in the experimental and control group over time. 
The improvement of BPSD after the first cycle and their worsening after the end of sessions suggests an effective connection between music therapy and the behavioural disorders reduction.

Our previous study (Raglio et al., 2008), had similar characteristics (sample, music therapy approach, number of sessions, etc.) but based on a continuous music therapy treatment (without wash-out periods), showed more generalised effects with regard to NPI global scores, NPI subscale items and the patients' communicative and relational skills in the music therapy setting. We believe that in that study the lack of interruption periods during the treatment plays an important role in the improvement of BPSD and of communicative and relational skills. Despite this difference between the two studies, the present study suggests a similar possible beneficial role of music therapy.

Active music therapy can amplify and strengthen the efficacy of therapeutic interventions towards people with dementia. Further studies are needed to delve into the specific effects of music therapy treatment on NPI subscale items and to investigate which duration and intensity (dose-effect) is optimal relating to different kinds and severity of dementia.

\section{References}

Raglio, A., Bellelli, G., Traficante, D., Gianotti, M., Ubezio, M.C., Gentile, S., ..., Trabucchi, M. (2008). Efficacy of music therapy treatment based on cycles of sessions: A randomised controlled trial. Aging \& Mental Health, 14, 900-904.

Raglio, A., Bellelli, G., Traficante, D., Gianotti, M., Ubezio, M.C., Villani, D., \& Trabucchi, M. (2010). Efficacy of music therapy in the treatment of behavioral and psychiatric symptoms of dementia. Alzheimer Disease and Associated Disorders, 22, 158-162. 